\title{
Sol-gel processing of carbidic glasses ${ }^{\dagger}$
}

\author{
L M MANOCHA*, E YASUDA ${ }^{\ddagger}$, Y TANABE ${ }^{*}, S$ MANOCHA and D VASHISTHA \\ Department of Materials Science, Sardar Patel University, Vallabh Vidyanagar 388 120, India \\ ${ }^{\ddagger}$ Materials and Structures Laboratory, Tokyo Institute of Technology, Nagatsuta, Yokohama 226, Japan
}

\begin{abstract}
Carbon incorporation into the silicate network results in the formation of rigid carbidic glasses with improved physical, mechanical and thermal properties. This generated great interest in the development of these heteroatom structured materials through different processing routes. In the present studies, sol-gel processing has been used to prepare silicon based glasses, especially oxycarbides through organic-inorganic hybrid gels by hydrolysis-condensation reactions in silicon alkoxides, 1,4-butanediol and furfuryl alcohol with an aim to introduce $\mathrm{Si}-\mathrm{C}$ linkages in the precursors at sol level. The incorporation of these linkages has been studied using IR and NMR spectroscopy. These bonds, so introduced, are maintained throughout the processing, especially during pyrolysis to high temperatures. In FFA-TEOS system, copolymerization with optimized mol ratio of the two results in resinous mass. This precursor on pyrolysis to $1000^{\circ} \mathrm{C}$ results in $\mathrm{Si}-\mathrm{O}-\mathrm{C}$ type amorphous solid black mass. XRD studies on the materials heated to $1400^{\circ} \mathrm{C}$ exhibit presence of crystalline $\mathrm{Si}-\mathrm{C}$ and cristobalites in amorphous $\mathrm{Si}-\mathrm{O}-\mathrm{C}$ mass. In organic-inorganic gel system, the pyrolysed mass exhibits phase stability up to much higher temperatures. The carbidic materials so produced have been found to exhibit good resistance against oxidation at $1000^{\circ} \mathrm{C}$.
\end{abstract}

Keywords. Sol-gel; silicon oxycarbide; organically modified inorganic gels; hydrolysis; pyrolysis; silicon carbide; cristoballites.

\section{Introduction}

Thermal stability and mechanical properties of silica glasses can be enhanced by cationic and anionic substitutions. This generated interest in investigating techniques to substitute divalent oxygen atoms by tetravalent carbon atoms in silica structure, thus making carbidic glasses (Leohman 1983; Renlund et al 1991; Soraru 1994). Conventional glass making techniques by melt processing of the constituents does not always produce glasses with desired microstructures due to high temperatures required for melting which in turn causes oxidation of carbon and thus result in non-homogeneous structure. The preparation of glasses via solution routes is currently of great interest since this can lead to the fabrication of monoliths with desired constituents and homogeneity at molecular level. Over past one decade or so, work has been reported by various groups to develop carbon incorporated silica network, the silicon oxycarbide glasses or so called, black glass using sol-gel technique with modified silicates of the type $R_{n}^{\prime} \mathrm{Si}(\mathrm{OR})_{4-n}$ as the starting material (Zhang and Pantano 1990; Mackenzie 1994; Babonneau et al 1994; Soraru et al 1995). The aim is to have silicon-carbon bond in the solution which may be carried on in the gel and sustain the high temperature pyrolysis. Present studies

†Paper presented at the 5th IUMRS ICA98, October 1998, Bangalore

*Author for correspondence have been performed using different sol-gel routes with unmodified silicates as source for silicon and using carbonaceous monomers and solvents as source for carbon. Following this route, the purpose is to introduce carbon containing organic groups in the molecular chain at the sol level during hydrolysis of TEOS and subsequent pyrolysis. The processing of gels and their pyrolysis at different temperatures to give carbidic glasses has been studied and reported here.

\section{Experimental}

Hybrid organic-inorganic gels were synthesized through two routes. In both the routes, the source of inorganic component was same, i.e. tetraethylorthosilicate (TEOS). The source of organic component was varied as furfuryl alcohol monomer and 1,4-butanediol. In route I, distilled furfuryl alcohol was added to hydrolyzed tetraethylorthosilicate under constant stirring. The ratio of TEOS to water and FFA was kept as $1: 8: 0.65$. In route II, tetraethylorthosilicate (TEOS) and 1,4-butanediol (BD) were mixed in $\mathrm{CCl}_{4}$ with molar ratios of TEOS : BD : $\mathrm{CCl}_{4}:: 1: 4: 2$. These ratios were optimized through a series of experiments to obtain gels of appropriate castable viscosity and desired $\mathrm{Si}, \mathrm{C}$ and $\mathrm{O}$ ratio in the ultimate product. The sols were cast in plastic petridishes and kept for gellation at room temperature. This was followed by gradual drying at $180^{\circ} \mathrm{C}$. This resulted in monolithic transparent material. Dried gel 
samples made by both routes were pyrolysed at $3^{\circ} \mathrm{C} / \mathrm{min}$ to $1000^{\circ} \mathrm{C}$ in presence of nitrogen. Some parts of the pyrolysed samples were further heated to $1400^{\circ} \mathrm{C}$ in nitrogen. The materials at gel stage as well as after heat treatment to different temperatures were characterized by Mettler Thermal Analysis system TA4000. The IR spectra were recorded using $\mathrm{KBr}$ pellet method on Hewlett Packard IR analyzer. X-ray diffraction studies were made on powdered samples using Rigaku X-ray diffractometer. NMR studies were made with JEOL FT NMR. The Raman spectra was recorded using Ar ion laser with Jobin Yvon/Atago Bussan T64000 triple spectrometer equipped with microscope optics.

\section{Results and discussion}

\subsection{Studies on $\mathrm{Si}, \mathrm{C}$, O network gels}

Tetraethylorthosilicate (TEOS) gets hydrolysed with water in presence of a catalyst according to the following reaction (Manocha et al 1997):

$$
\mathrm{Si}(\mathrm{OR})_{4}+4 \mathrm{H}_{2} \mathrm{O}=\mathrm{Si}(\mathrm{OH})_{4}+4 \mathrm{ROH} .
$$

The ethoxy groups are replaced by hydroxyl groups. Further condensation reactions take place in $\mathrm{Si}(\mathrm{OH})_{4}$ resulting in gellation and polymerization to silica network. Furfuryl alcohol monomer also gets polymerized in presence of hydroxyl groups. Following this scheme, furfuryl alcohol monomer was added to hydrolysed TEOS (before gellation) so that the two copolymerized in presence of hydroxyl groups. In case of TEOS/butanediol system, the hydrolysis of TEOS takes place due to alcohol group in 1,4-butanediol as per following reaction (Amara 1994):

$$
\mathrm{Si}-(\mathrm{OR})_{4}+\mathrm{HO}-\left(\mathrm{CH}_{2}\right)_{4}-\mathrm{OH} \Rightarrow \mathrm{Si}-\mathrm{O}-\left(\mathrm{CH}_{2}\right)_{4}-\mathrm{O}-\mathrm{Si}+2 \mathrm{ROH} \text {. }
$$

In this case, 1,4-butanediol effects both hydrolysis of TEOS and incorporation of carbon aromatic group in the molecular chain. The gelled samples were characterized by IR spectroscopy. Figure 1 shows IR spectra of dried gels made from the two systems. The spectra of gels show characteristic peaks at around $460 \mathrm{~cm}^{-1}$ and $800 \mathrm{~cm}^{-1}$ associated with $\mathrm{Si}-\mathrm{O}-\mathrm{Si}$ bond bending and symmetric bond stretching vibrations respectively. The band at $960 \mathrm{~cm}^{-1}$ is associated with stretching mode $\mathrm{Si}-\mathrm{OH}$ and at $1220 \mathrm{~cm}^{-1}$ associated with LO mode of Si-O-Si asymmetric bond stretching vibration (Yoshino et al 1990). The intensities of these bands decrease during hydrolysis/ condensation in presence of furfuryl alcohol. The spectra of FFA/TEOS gel system show peaks at $1300-1400 \mathrm{~cm}^{-1}$ due to alkyl bonding to silicon. Absence of a sharp peak around $1500 \mathrm{~cm}^{-1}$ assigned to furan rings suggests the reaction between $\mathrm{Si}-\mathrm{OH}$ group of silica sol and $-\mathrm{OH}$ group of furfuryl alcohol during gellation and copolymerization. In TEOS/BD system, the intensities of the peak at $960 \mathrm{~cm}^{-1}$ and that of the band around $1170 \mathrm{~cm}^{-1}$ change with addition of butanediol. These decrease with increased butanediol content. This suggests that alcohol group of butanediol and ethoxy groups in TEOS are reacting. The hybrid gels show additional bands $\left(\mathrm{v}_{\mathrm{OH}}\right.$ at around $3400 \mathrm{~cm}^{-1}, v_{\mathrm{CH}}$ at $2940-2880 \mathrm{~cm}^{-1}, \delta_{\mathrm{CH}}$ at

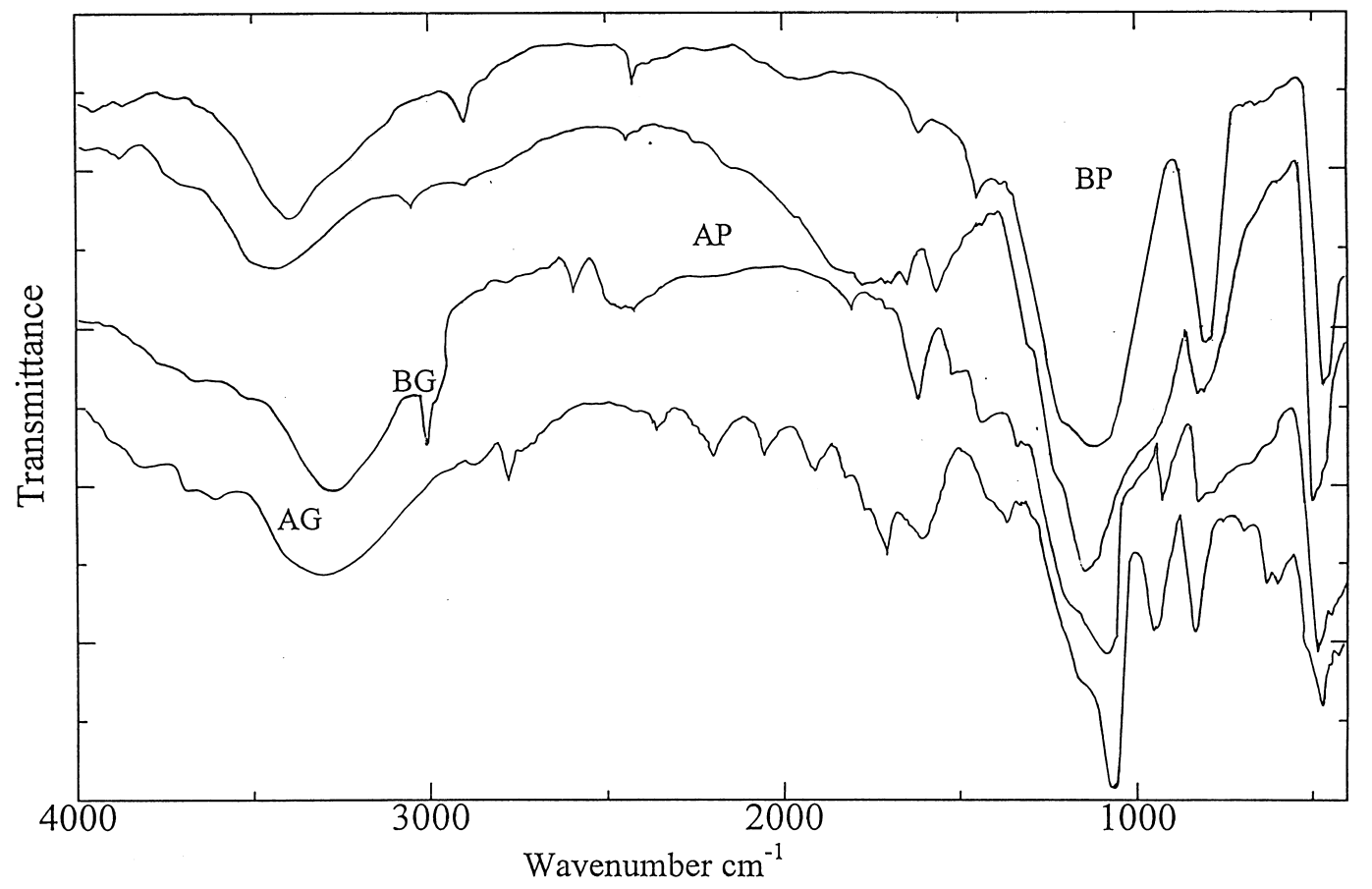

Figure 1. IR spectra of dried gels at $180^{\circ} \mathrm{C}$ and after pyrolysis to $1000^{\circ} \mathrm{C}$ (AG (TEOS/FFA gel), AP (TEOS/FFA pyrolysed), BG (TEOS/BD gel), and BP (TEOS/BD pyrolysed)). 
$1480-1440 \mathrm{~cm}^{-1}$ and $\delta_{\mathrm{OH}}$ around $1380 \mathrm{~cm}^{-1}$ ) due to butanediol. The presence of two bands at 1080 and $840 \mathrm{~cm}^{-1}$ might be due to $\mathrm{Si}-\mathrm{O}$ vibration in $\mathrm{Si}-\mathrm{O}-\mathrm{C}$ and $\mathrm{Si}-\mathrm{O}-\mathrm{Si}$. The peak around $2300 \mathrm{~cm}^{-1}$ and low intensity peaks around $1260 \mathrm{~cm}^{-1}$ and $1360 \mathrm{~cm}^{-1}$ are due to $\mathrm{CH}_{2}$ groups. These results show that TEOS is getting hydrolyzed by the $-\mathrm{OH}$ groups in butanediol with a result, the $\mathrm{CH}_{2}$ groups are getting incorporated in the chain. The $\mathrm{Si}-\mathrm{C}$ linkage is also evident from ${ }^{29} \mathrm{Si}$ NMR spectra of the gelled sample shown in figure 2 . The shifts between -15 to $-70 \mathrm{ppm}$ are assigned to various $\mathrm{Si}, \mathrm{C}, \mathrm{O}$ linkages. These studies show that in both the routes, carbon containing components are introduced in the $\mathrm{Si}-\mathrm{O}$ gel network.

\subsection{Pyrolysis of gelled samples to $\mathrm{Si}-\mathrm{O}-\mathrm{C}$ glasses}

The dried gel samples were transparent like tough plastics. The pyrolysis of the dried gels to $1000^{\circ} \mathrm{C}$ was studied by thermal techniques. Figure 3 shows TGA and DSC plots of the organic-inorganic hybrid gels. The dried gels exhibit an endothermic peak below $200^{\circ} \mathrm{C}$ and an exothermic peak above $400^{\circ} \mathrm{C}$. Similarly, TGA plots show that the pyrolysis occurs mainly over two temperatures, low $200^{\circ} \mathrm{C}$ and a steady weight loss between 400 and $700^{\circ} \mathrm{C}$, characteristic of condensation reactions and decomposition/rearrangement reactions in carbonaceous materials. The endothermic peak and weight loss below $200^{\circ} \mathrm{C}$ are associated with condensation reactions and evaporation of reaction products and residual water. The extent of these have been found to be lower than those for pure silica gels. The weight loss after $400^{\circ} \mathrm{C}$ is assigned to condensation of silanol groups and formation of inorganic network with removal of hydrogen containing compounds etc. Thermal cracking of hydrocarbon groups also results

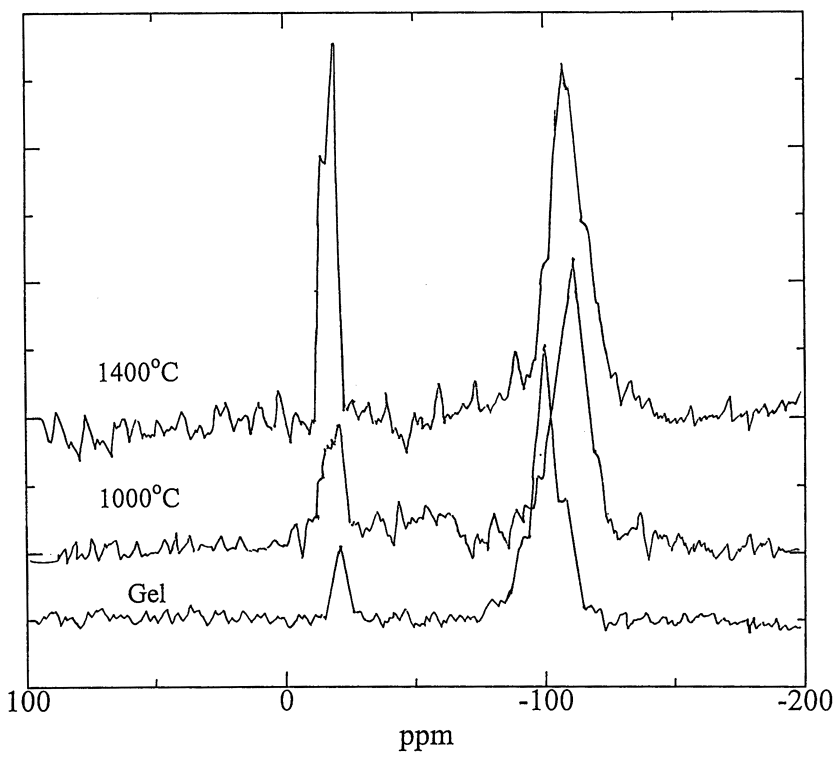

Figure 2. ${ }^{29} \mathrm{Si}$ NMR spectra of the gelled samples and samples heated to $1000^{\circ} \mathrm{C}$ and $1400^{\circ} \mathrm{C}$. in weight loss in this temperature range. The presence of exotherm in this temperature range suggests that a ring opening reaction (furan rings in FFA/TEOS systems) and thermal cracking of hydrocarbon $\mathrm{CH}_{2}$ groups may also be taking place. This suggests that condensation of silanol groups and chain opening reactions are going on simultaneously. This may result in $\mathrm{Si}-\mathrm{C}, \mathrm{Si}-\mathrm{O}-\mathrm{C}$ type of bonding.

\subsection{Characterization of pyrolysed ( $\mathrm{Si}-\mathrm{O}-\mathrm{C})$ materials}

On pyrolysis to $1000^{\circ} \mathrm{C}$, all samples resulted in fragmented, shining black, brittle, hard materials. The IR spectra of pyrolysed samples are shown in figure 1. On pyrolysis of the samples to $1000^{\circ} \mathrm{C}$, the bands at $570 \mathrm{~cm}^{-1}$, $960 \mathrm{~cm}^{-1}$ and $1630 \mathrm{~cm}^{-1}$ disappeared while those at $790 \mathrm{~cm}^{-1}$ and $470 \mathrm{~cm}^{-1}$ became more prominent suggesting presence of $\mathrm{SiO}_{4}$ tetrahedron. Broadness of the peak at $800 \mathrm{~cm}^{-1}$ and of band at $1000-1250 \mathrm{~cm}^{-1}$ may presumably be due to simultaneous development of some overlapping peaks such as at $820 \mathrm{~cm}^{-1}$ due to $\mathrm{Si}-\mathrm{C}$ linkages, at $1080 \mathrm{~cm}^{-1}$ due to $\mathrm{Si}-\mathrm{O}-\mathrm{C}$, and at $1120 \mathrm{~cm}^{-1}$ due to $\mathrm{Si}-\mathrm{C}$ etc. A small peak at $1360 \mathrm{~cm}^{-1}$ is observed in the pyrolysed samples. This may be due to carbonaceous materials as a result of cracking of hydrocarbon groups. In addition, the IR spectra of pyrolysed samples also show doublet at $830-850 \mathrm{~cm}^{-1}$ suggesting that some of the silicon atoms are bonded to carbon atoms (Renlund et al 1991). Thus the material appears to be a complex mixture containing $\mathrm{Si}-\mathrm{O}, \mathrm{Si}-\mathrm{C}$ and $\mathrm{C}=\mathrm{C}$ linkages.

This is further supported by NMR spectra of the pyrolyzed samples (figure 2). The shift between $-15 \mathrm{ppm}$ and $-25 \mathrm{ppm}$ is assigned to a mixture of $\mathrm{SiC}_{4}$ and $\mathrm{SiC}_{3} \mathrm{O}$, while the one at -110 is assigned to cristobalite structure. Raman spectra (figure 4) of the pyrolysed samples confirms that free carbon present is of amorphous type, similar to the glassy carbons from polyfurfuryl alcohol. XRD spectra (figure 5) of the pyrolysed samples also show that the material is amorphous. The broad band around $2 \theta=22^{\circ}$ may be due to combined amorphous carbon and amorphous silica structures and hence of silicon oxycarbide family.

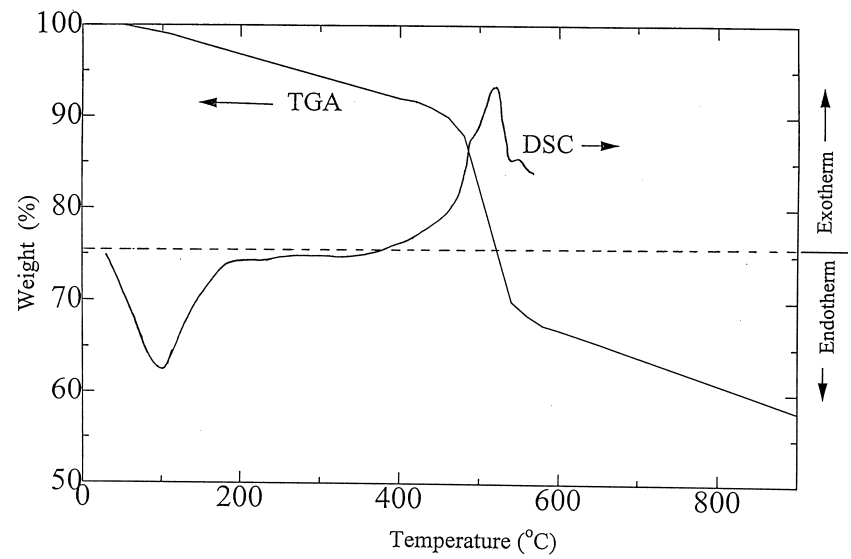

Figure 3. TGA and DSC plots in nitrogen for gel samples. 


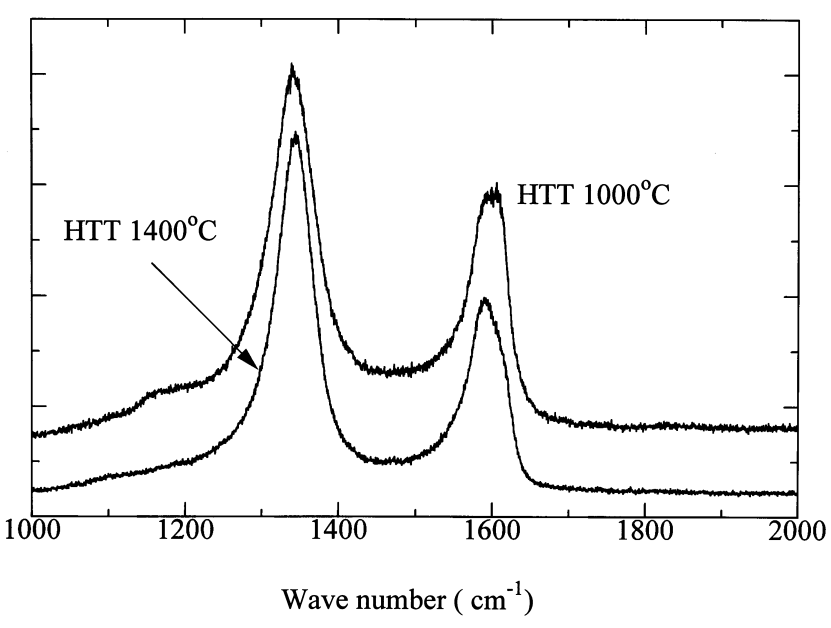

Figure 4. Raman spectra of the samples heat treated to $1000^{\circ} \mathrm{C}$ and $1400^{\circ} \mathrm{C}$.

On further heating to $1400^{\circ} \mathrm{C}$, the material initially in the powder form turned to black lump form. XRD of the samples heated at $1400^{\circ} \mathrm{C}$ show development of crystalline phases in amorphous black glass. The sample heated to $1400^{\circ} \mathrm{C}$ exhibits a band around $2 \theta=21^{\circ}(d=0.35$ $0.45 \mathrm{~nm})$ with a sharp peak at $2 \theta=21.7^{\circ}(d=0.408 \mathrm{~nm})$ due to cristobalite $\mathrm{SiO}_{2}$. The peak at $2 \theta=35 \cdot 8^{\circ}(d=$ $0.25 \mathrm{~nm}$ ) suggests development of small crystallites of silicon carbide. Peaks of lower intensities at $2 \theta=45.6^{\circ}$ and $48.3^{\circ}$ with $d$ values $0.198 \mathrm{~nm}$ and $0.188 \mathrm{~nm}$ respectively occurred presumably due to $\mathrm{SiO}_{2}$.

\subsection{Oxidation studies on black glasses}

One of the major considerations in developing silicon oxycarbide materials is to obtain a thermally stable material under oxidizing conditions. Therefore, black glasses obtained by heat treatment of above stated hybrid organic-inorganic gels were evaluated for resistance towards oxidation by heating the samples at $1000^{\circ} \mathrm{C}$ for $2 \mathrm{~h}$ under flowing oxygen. Weight loss was recorded after the experiment. Materials at $1000^{\circ} \mathrm{C}$ from the gels with $\mathrm{BD} / \mathrm{TEOS}$ system exhibited negligible weight loss of $0.6 \%$. On heat treatment to $1400^{\circ} \mathrm{C}$, all the samples show almost same weight loss, higher than those heated at $1000^{\circ} \mathrm{C}$. This carbon may be well encapsulated in the crystobalite phase.

\section{Conclusion}

The present studies were performed to develop silicon oxycarbide from organic-inorganic hybrid gels starting from unsubstituted silicate (TEOS) and carbon containing monomers. From the present studies it is concluded that sol-gel process gives a wider scope to add carbon con-

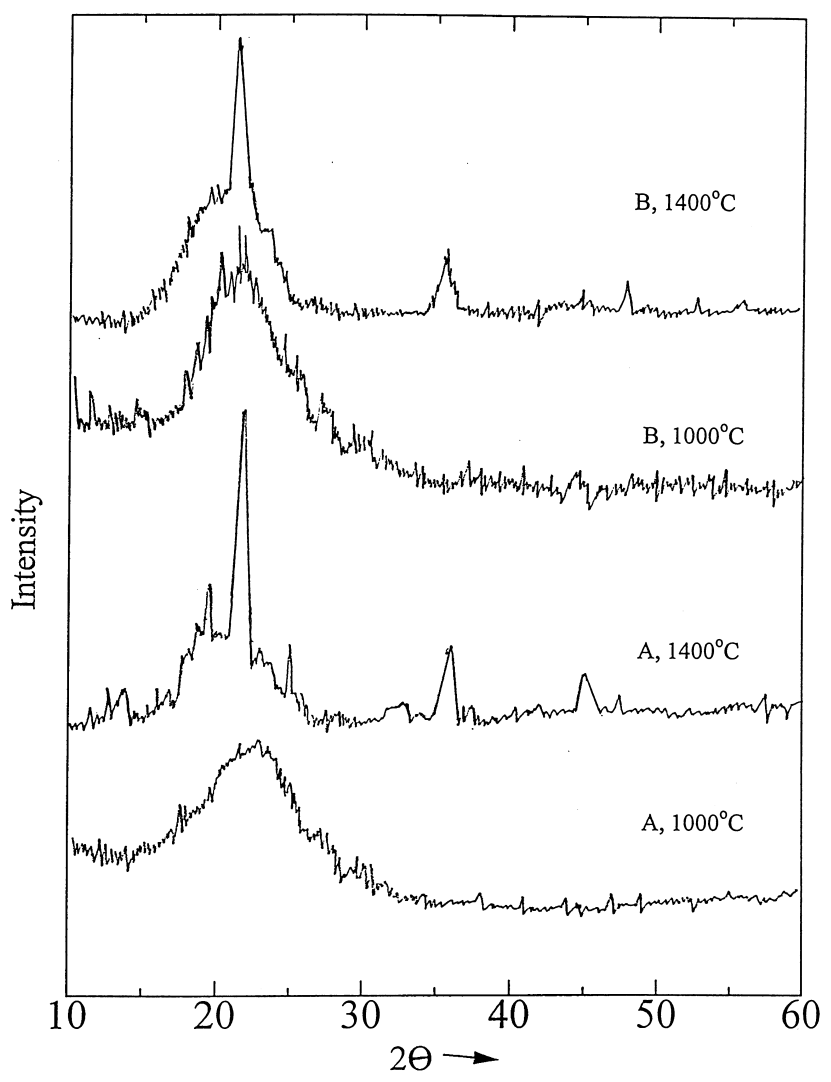

Figure 5. XRD patterns of silicon oxycarbide samples made with (A) TEOS/FFA and (B) TEOS/BD systems.

taining organic molecules in the silicate network structures at sol stage. TEOS gets hydrolysed by butanediol, which additionally, incorporates carbon containing groups in the so called organic-inorganic hybrid gels. These hybrid gels on pyrolysis, result in good oxidation resistance oxycarbidic glasses. On heat treatment to a temperature around $1400^{\circ} \mathrm{C}$, crystalline phase of $\mathrm{SiC}$ develops within the amorphous black glass. The onset temperature depends largely on the molecular nature and amount of additives.

\section{References}

Amara Ch. Ben, Gharbi N and Zarrouk H 1994 J. Sol-gel Sci. \& Technol. 2193

Babonneau F et al 1994 Chem. Mater. 651

Leohman R E 1983 J. Non-Cryst. Solids 56123

Mackenzie J D 1994 J. Sol-gel Sci. \& Technol. 281

Manocha S M, Vashistha D Y and Manocha L M 1997 J. Mater. Sci. Lett. 16705

Renlund G M, Prochazke S and Doremus R H 1991 J. Mater. Res. 62716

Soraru G D 1994 J. Sol-gel Sci. \& Technol. 2843

Soraru G D et al 1995 J. Am. Ceram. Soc. 78379

Yoshino H, Kamiya K and Nasu H 1990 J. Non-Cryst. Solids 12668

Zhang H and Pantano C G 1990 J. Am. Ceram. Soc. 73958 